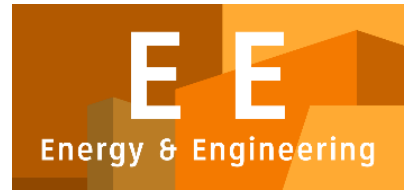

PAPER - OPEN ACCESS

\title{
Studi Fluiditas dan Karakteristik Aliran pada Pengecoran Al-Si Alloy Menggunakan Simulasi Numerik
}

\author{
Author \\ : Andri Willy Adianta \\ DOI \\ ISSN \\ : 10.32734/ee.v1i1.102 \\ E-ISSN \\ : 2654-7031 \\ : 2654-704X
}

Volume 1 Issue 1 - 2018 TALENTA Conference Series: Energy and Engineering

\section{(a) $(\mathbb{\theta})$}

This work is licensed under a Creative Commons Attribution-NoDerivatives 4.0 International License.

Published under licence by TALENTA Publisher, Universitas Sumatera Utara
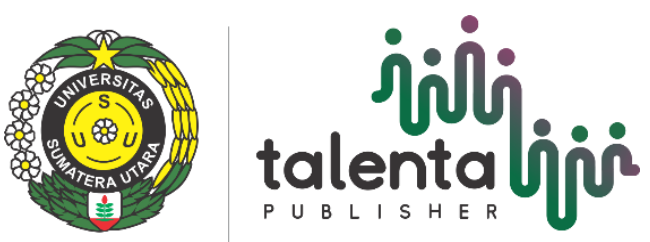


\title{
Studi Fluiditas dan Karakteristik Aliran pada Pengecoran Al-Si Alloy Menggunakan Simulasi Numerik
}

\author{
Andri Willy Adianta ${ }^{a^{*}}$, Suprianto ${ }^{\mathrm{a}}$, Arnius Daely ${ }^{\mathrm{a}}$, Mikael F. Bangun ${ }^{\mathrm{a}}$ \\ ${ }^{a}$ Fakultas Teknik, Universitas Sumatera Utara, Medan, 20155
}

\begin{abstract}
Abstrak
Aluminium silikon alloy merupakan paduan aluminium yang banyak digunakan dalam bidang teknik. Paduan ini memiliki kekuatan yang baik dan banyak diproduksi menjadi suatu komponen melalui proses pengecoran. Kandungan silikon dapat mengakibatkan penurunan fluiditas coran alumunium yang pada akhirnya akan menurunkan kualitas coran, fluiditas ini juga dipengaruhi temperatur pada saat penuangan alumunium cair. Penelitian ini bertujuan untuk mengetahui efek temperatur penuangan terhadap fluiditas, karakteristik aliran dan cacat coran pada pengecoran aluminium silikon alloy menggunakan cetakan pasir. Pengecoran dilakukan dengan gravity casting, analisa aliran simulasi meliputi distribusi kecepatan aliran, temperatur, tekanan, cacat permukaan dan fluiditas yang terjadi pada saat proses pengisian rongga cetak serta perbandingan fluiditas coran dan cacat permukaan pada eksperimental. Temperatur penuangan $685,710,735,760$ dan $785^{\circ} \mathrm{C}$ dengan ketebalan cetakan pola 1, 3, 5, 7, 9, dan $12 \mathrm{~mm}$. Proses simulasi menggunakan software berbasis computational fluid dynamic. Hasil penelitian diperoleh temperatur tuang $785^{\circ} \mathrm{C}$ memiliki kecepatan aliran tertinggi yaitu sebesar $\pm 0.145 \mathrm{~m} / \mathrm{s}$ pada rongga $12 \mathrm{~mm}$ dan distribusi temperatur yang tinggi yaitu sebesar $\pm 759^{\circ} \mathrm{C}$ pada rongga $3 \mathrm{~mm}$, sedangkan temperatur tuang $685^{\circ} \mathrm{C}$ memiliki distribusi tekanan yang tinggi yaitu sebesar \pm 107287 Pa pada rongga $6 \mathrm{~mm}$. Cacat permukaan terbanyak pada temperatur tuang $785^{\circ} \mathrm{C}$ dan temperatur tuang $685^{\circ} \mathrm{C}$ paling sedikit. Fluiditas coran terbaik pada temperatur $785^{\circ} \mathrm{C}$ dimana rongga $12,9,7,5$ dan 3 $\mathrm{mm}$ terisi penuh dan $1 \mathrm{~mm}$ mencapai $181.4 \mathrm{~mm}$.
\end{abstract}

Kata kunci: Analisis Numerik; Fluiditas; Karakteristik aliran; Aluminium; Coran

\section{Pendahuluan}

Industri pengecoran logam meningkat seiring dengan perkembangan teknologi.Terdapat banyak produk hasil cor yang sering kita jumpai mulai dari perabotan rumah, komponen otomotif, dan peralatan industri. Permintaan pasar akan produk logam cor yang tinggi kurang diimbangi dengan peningkatan kualitas produk yang dihasilkan sehingga banyak kita jumpai produk dengan kualitas yang rendah yaitu banyaknya cacat yang timbul pada produk cor khususnya pada pengecoran menggunakan cetakan pasir, salah satunya yaitu cacat permukaan[8].

Kualitas dari hasil coran dengan menggunakan metode gravity casting pada cetakan pasir dipengaruhi oleh cetakan (mold), sifat fluiditas logam cair, desain sistemsaluran, pola cetakan dan temperatur penuangan. faktor faktor tersebut saling berhubungan satu sama lainya sehingga sulit untuk mengoptimasikanya [13]. Bentuk akhir produk coran sangat tergantung pada kemampuan fluiditas logam cair. Panjang fluiditas sangat tergantung pada temperatur penuangan [12], sedangkan tingginya temperatur penuangan dapat memicu kecepatan aliran yang tinggi yang bisa mengakibatkan turbulensi yang tinggi dimana turbulensi yang tinggi dapat memicu cacat permukaan [8].

Cacat pada permukaan coran dapat dielaminir dengan salah satunya dengan melakukan optimasi pada temperatur penuangan. pada umumnya untuk mengelaminir cacat coran yaitu dengan melakukan trial and error, metode ini 
memakan biaya dan waktu yang banyak sehingga dapat mengakibatkan besarnya biaya dan waktu produksi. Simulasi numerik adalah opsi untuk mengurangi trial and error [13], biasanya untuk optimasi proses pengecoran digunakan software berbasis CFD [5]. Salah satu software komputer yang mampu mengaplikasi desain pengecoran ini yaitu software flow-3d. Program desain grafis tiga dimensi ini mampu menampilkan suatu produk atau hasil akhir seperti benda sesungguhnya sebelum proses pembuatan benda kerja dilakukan sehingga suatu produk dapat diketahui bentuk dan dan dapat dianalisa karakteristiknya sebelum diproduksi [7].

\subsection{Metode Penelitian}

Pada penelitian ini material coran menggunakan aluminium A356 dan material cetakan menggunakan pasir silika. Pengecoran gravity casting dengan variasi temperatur penuangan $685,710,735,760$ dan $785^{\circ} \mathrm{C}$. Pengujian fluiditas menggunakan metode Birmingham (Gambar 1) analisis distribusi tekanan, kecepatan, temperatur serta prediksi cacat coran menggunakan software berbasis CFD.

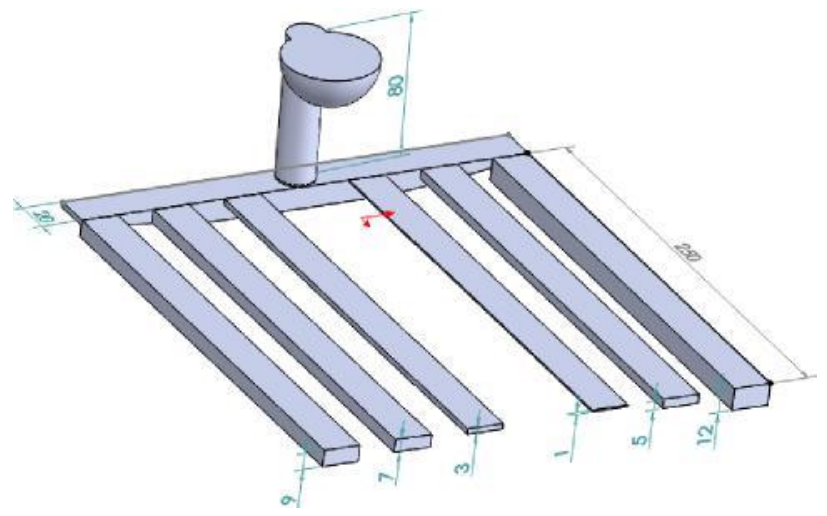

Gambar 1. Dimensi pola cetakan

\section{Hasil Penelitian}

\subsection{Hasil Simulasi Fluiditas aluminium A356}

Analisis fluiditas aliran bertujuan untuk mengetahui kemampuan alir cairan logam yang mengalir masuk ke dalam cetakan pada saat 6 detik. Hasil pengukuran diperlihatkan Gambar 2 berikut :

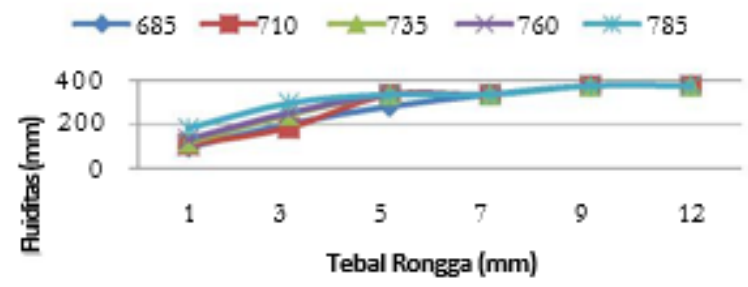

Gambar 2. Grafik fluiditas terhadap perbedaan ketebalan benda cor

Gambar 2 di atas dapat dilihat bahwa fluiditas terendah yaitu pada temperatur tuang $685^{\circ} \mathrm{C}$, hal ini disebabkan karena temperatur penuangan sudah mendekati temperatur solid cairan aluminium A356 yaitu $552.4{ }^{\circ} \mathrm{C}$ dan juga dapat kita lihat pada grafik diatas bahwa fluiditas terendah pada setiap temperatur penuangan yaitu pada rongga yang paling kecil rongga $1 \mathrm{~mm}$ hal ini disebabkan karena rongga saluran yang kecil sehingga mengakibatkan meningkatnya tegangan permukaan [2]

Faktor-faktor yang mempengaruhi nilai fluiditas adalah temperatur (derajat superheat), komposisi kimia, 
tegangan permukaan, konduktifitas material cetakan, inklusi dan viskositas [6].

\subsection{Distribusi Kecepatan}

Analisis distribusi kecepatan bertujuan untuk mengetahui karakteristik kecepatan cairan logam yang mengalir masuk ke dalam cetakan pada saat 6 detik. Hasil pengukuran di perlihatkan Gambar 3 berikut:

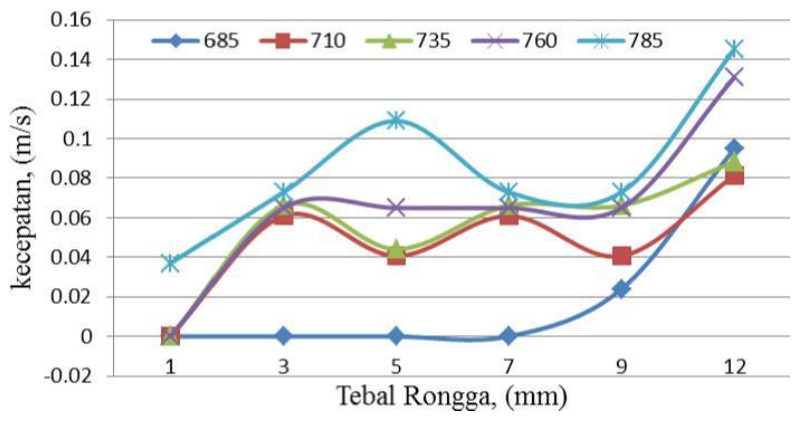

Gambar 3. Grafik distribusi kecepatan terhadap perbedaan ketebalan benda cor

Gambar 3 memperlihatkan kontur kecepatan dan pola aliran pada setiap temperatur penuangan. Kecepatan aliran tertinggi terdapat pada temperatur tuang $785^{\circ} \mathrm{C}$ pada rongga 12 mmyaitu sebesar $\pm 0,145 \mathrm{~m} / \mathrm{s}$. Hal ini dikarenakan kecepatan aliran hanya terfokus ke rongga $12 \mathrm{~mm}$. Sedangkan kecepatan fluida terendah terjadi pada temperatur tuang $685^{\circ} \mathrm{C}$ rongga $1,3,5$ dan $7 \mathrm{~mm}$ yaitu sebesar $0 \mathrm{~m} / \mathrm{s}$. Hal ini dikarenakan aluminium pada rongga 1 $\mathrm{mm}$ sudah membeku sehingga tidak ada aliran yang terjadi.

Pengaruh temperatur tuang terhadap fluiditas viskositas dan tegangan permukaan logam cair akan berkurang dengan bertambahnya temperatur tuang yang menyebabkan bertambahnya kecepatan pengisian. Hal inilah yang menyebabkan panjang fluiditas meningkat seiring meningkatnya temperatur penuangan. Tren peningkatan seperti ini juga dinyatakan [12].

Kecepatan aliran yang tinggi juga dapat memicu terjadinya turbulensi. Semakin besar turbulensi yang terjadi maka akan semakin besar pula kemungkinan cacat yang ada pada produk hasil coran. Hal ini terjadi karena akan mempermudah terjebaknya gas-gas yang ada pada saat proses penuangan logam cair [11]. Hal ini dapat dicegah dengan mensimulasikan berbagai variasi tempratur tuang hingga tercapai kecepatan rata-rata yang paling minimum.

Kecepatan aliran yang tinggi juga dapat menurunkan tekanan aliran hal ini di tunjukan pada hukum Bernoulli dimana jika P2>P1 maka V1>V2 sehingga semakin besar tekanan pada P2 maka tekanan kecepatan pada V2 akan semakin kecil.

\subsection{Distribusi Temperatur}

Analisis distribusi tempratur bertujuan untuk mengetahui karak teristik suhu cairan logam yang mengalir masuk ke dalam cetakan pada saat 6 detik.hasil pengukuran di perlihatkan Gambar 4 berikut:

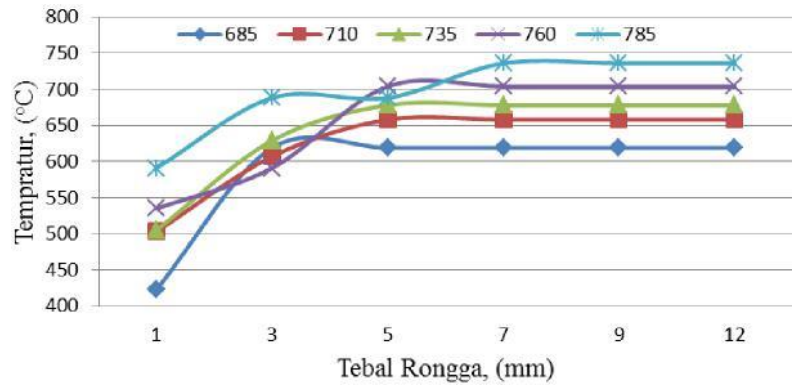

Gambar 4. Grafik distribusi temperatur terhadap perbedaan ketebalan benda cor 
Gambar 4 memperlihatkan bahwa temperatur tertinggi didapat pada temperatur tuang $785{ }^{\circ} \mathrm{C}$ yaitu pada rongga 7, 9 dan $12 \mathrm{~mm}$ sebesar $736^{\circ} \mathrm{C}$, kemudian temperatur tuang $685^{\circ} \mathrm{C}$ memiliki temperatur terendah yaitu pada rongga $1 \mathrm{~mm}$ sebesar $423{ }^{\circ} \mathrm{C}$. Hal ini dikarenakan temperatur tuang $685^{\circ} \mathrm{C}$ mengalami kehilangan panas terbesar dikarenakan kehilangan temperatur pada lintasan yang dilalui oleh aliran logam cair saat memasuki cetakan.

Ketebalan yang minimum mempengaruhi terhadap volume coran yang melewati saluran yang artinya logam cair dalam volume kecil akan lebih cepat kehilangan panas dibanding yang bervolume besar, semakin lama logam dalam keadaan cair akan meningkatkan waktu pembekuan. peningkatan waktu pembekuan akan memberi kesempatan logam cair untuk mengalir [2].

Temperatur tuang yang tinggi juga akan menambah waktu pembekuan, semakin besar waktu pembekuan semakin panjang aliran logam. Peningkatan panjang logam cair untuk mengisi rongga yang tipis sangat kecil dibanding pada rongga yang tebal [11]

\subsection{Distribusi Tekanan}

Analisis distribusi tempratur bertujuan untuk mengetahui karak teristik suhu cairan logam yang mengalir masuk ke dalam cetakan pada saat 6 detik.hasil pengukuran di perlihatkan Gambar 4 berikut:

Berdasarkan Gambar 5, dapat dilihat tekanan maksimum terjadi pada temperatur tuang $735^{\circ} \mathrm{C}$ pada rongga $5 \mathrm{~mm}$ yaitu sebesar 101635 pa dan terendah pada rongga $7 \mathrm{~mm}$ temperatur tuang $785^{\circ} \mathrm{C}$ yaitu sebesar 99343 pa.

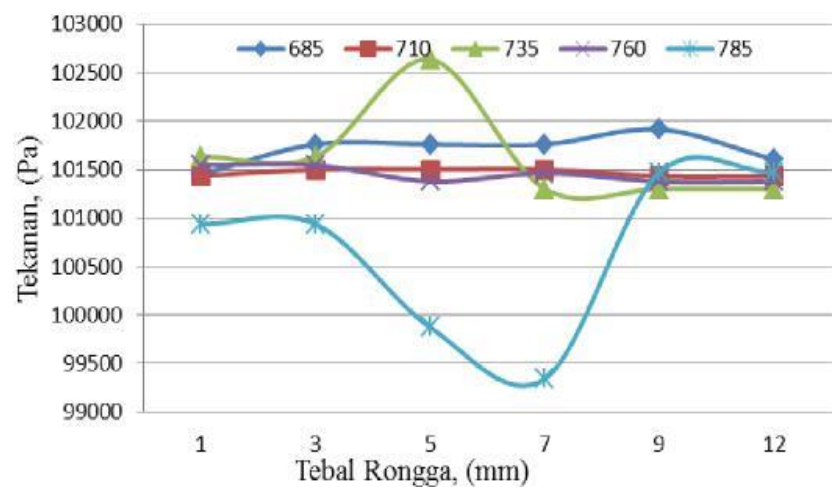

Gambar 5. Grafik distribusi tekanan terhadap perbedaan ketebalan benda cor

Pengaruh tekanan terhadap aliran logam cair, [9] menyatakan tekanan menyebabkan panjang fluiditas bertambah dengan menurunnya solidus temperatur [9]. Logam cair dapat mengalir pada fraksi solid tinggi dan berhenti saat temperatur mendekati temperatur solidus. Pemberian tekanan yang terkontrol pada logam cair dapat menentukan pola aliran pada saluran dalam cetakan [11].

Pemberian tekanan pada cairan logam menghasilkan hasil coran dengan bentuk mendekati ukuran akhir atau bentuk kesempurnaannya (near-net shape) dan dapat meminimalisir cacat coran [11]. 


\subsection{Konsentrasi Cacat Permukaan}

Berikut ini adalah hasil simulasi cacat permukaan (surface defect concentration) yang terjadi pada bagian bawah coran.

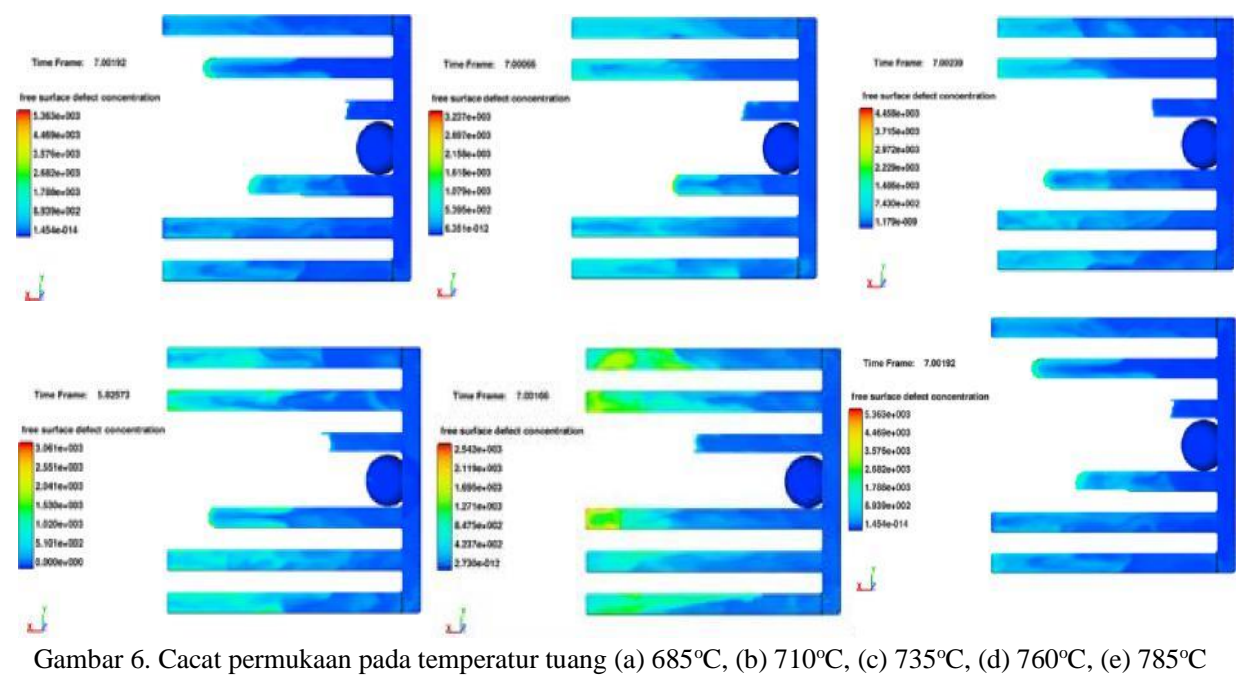

Gambar 6 memperlihatkan cacat permukaan pada temperatur tuang 785 lebih banyak seperti ditunjukkan oleh kontur berwarna kuning-kehijauan pada pada Gambar 5 (e) sedangkan cacat permukaan yang paling sedikit terjadi pada temperatur penuangan 685 seperti ditunjukkan oleh kontur berwarna kuning-kehijauan pada pada Gambar 5 (a).

Pada banyak kasus, mayoritas terperangkapnya inklusi gas/zat pengotor terdapat pada daerah cetakan yang diisi paling akhir, dengan kata lain inklusi dan zat pengotor akan terdorong oleh arus aliran logam hingga ke daerah yang paling luar.

\section{Kesimpulan}

Hasil simulasi berupa kontur kecepatan menunjukkan kecepatan tertinggi yaitu pada temperatur tuang $785^{\circ} \mathrm{C}$ yaitu $\pm 0.145 \mathrm{~m} / \mathrm{s}$ sedangkan kecepatan fluida terendah terjadi pada model saluran temperatur tuang $685{ }^{\circ} \mathrm{C}$ dimana kecepatan pada rongga 1, 3, 5 dan $7 \mathrm{~mm}$ sudah mencapai $0 \mathrm{~m} / \mathrm{s}$.

Temperatur tertinggi terdapat pada temperatur tuang $785^{\circ} \mathrm{C}$ yaitu pada rongga $3,5,7,9$ dan $12 \mathrm{~mm}$ sebesar $\pm 737^{\circ} \mathrm{C}$, sedangkan temperatur terendah pada temperatur tuang $685^{\circ} \mathrm{C}$ rongga $1 \mathrm{~mm}$ sebesar $\pm 446^{\circ} \mathrm{C}$.

Tekanan tertinggi terjadi pada temperatur tuang $760^{\circ} \mathrm{C}$ pada rongga $12 \mathrm{~mm}$ sebesar $\pm 107287 \mathrm{~Pa}$ pada detik ke 6 sementara tekanan terendah terdapat pada temperatur tuang $785^{\circ} \mathrm{C}$ yaitu pada rongga $7 \mathrm{~mm}$ sebesar 99343 pa. Konsentrasi cacat permukaan terbanyak ditemukan pada temperatur tuang $785^{\circ} \mathrm{C}$ sedangkan yang paling sedikit pada temperatur tuang $685^{\circ} \mathrm{C}$.

Hasil simulasi fluiditas terbaik didapat pada tempratur tuang $785^{\circ} \mathrm{C}$, Hal ini dikarenakan rongga 12, 9, 7, 5 dan 3 $\mathrm{mm}$ terisi penuh sedangkan pada rongga $1 \mathrm{~mm}$ panjang fluiditas mencapai $181.4 \mathrm{~mm}$. Fluiditas terburuk yaitu pada tempratur tuang $685^{\circ} \mathrm{C}$ terdapat tiga rongga yang tidak terisi yaitu rongga $5 \mathrm{~mm}$ sepanjang $281 \mathrm{~mm}, 3 \mathrm{~mm}$ sepanjang $201 \mathrm{~mm}$ dan $1 \mathrm{~mm}$ sepanjang $95.5 \mathrm{~mm}$. 


\section{Referensi}

[1] ASM Specialty Handbook, (1993)," Aluminium and Aluminium Alloys", Ohio, USA.

[2] Campbell, J. and Harding, R.A.,(1994), - The Fluidity of Molten Metals", Training in Aluminium Application Technologies (Talat) Lecture 3205, p.p. 2-4.

[3] Dedy Masnur dan Suyitno “Pengaruh Temperatur Tuang dan Ketebalan Coran terhadap Fluiditas ADC 12pada High Pressure Die Casting (HPDC)” National Seminar RETII STTNAS-Yogyakarta 2008

[4] Di Sabatino, M., Arnberg, L. and Bonollo, F. (2005), "Simulation of fluidity in Al-Si alloys", Metallurgical Science and Technology, vol. 23, no. 1, pp. 3-10.

[5] F. Bonollo and S. Odorizzi, SGE Ed., (2001). "Numerical Simulation of Foundry Processes“ ‘ Padova.

[6] Flemings, M.C., 1974, "Solidification Processing", McGraw-Hill Book Company, New York. Flow -3D(R), Aachen, Germany, 2001.

[7] Indra, Ahmad S. \& Ridwan (2012) "Analisa Aliran Fluida Pada Pipa SpiralDengan Variasi Diameter Menggunakan Metode Computational FluidDinamics (CFD)" Jurusan Teknik Mesin, Fakultas Teknologi Industri, Universitas Gunadarma.

[8] Kusharjanta, Bambang. (2011), "Kajian Letak Saluran Masuk (Ingate) Terhadap Cacat Porositas, Kekerasan, Dan Ukuran Butir Paduan Aluminium Pada Pengecoran Menggunakan Cetakan Pasir”, Jurnal Vol. 10 No. 1, Jurusan Teknik Mesin - Universitas Sebelas Maret.

[9] Q.Y. Han and H.B. Xu, Fluidity of Alloys Under High Pressure Die Casting Conditions, Scr. Mater., 2005, 53, p 7-10

[10] Qudong, W., Yizhen, Lu, Xiaoqin, Z., Wenjiang, D., Yanping, Z., Qinghua, L., dan Jie, L., (1999), "Study on Fluidity of AZ91+xRE Magnesium Alloy“, Elsevier.

[11] S. M. Respati, Bondan, H. Purwanto \& M. S. Mauluddin, "Pengaruh Tekanan Dan Temperatur Cetakan Terhadap Struktur Mikro Dan Kekerasan Hasil Pengecoran Pada Material Aluminium Daur Ulang” Teknik Mesin Fakultas Teknik, Universitas Wahid Hasyim, Semarang.

[12] Sabatino, M. D., Arnberg, L., Brusethaug, S., dan Apelian, D., (2006), -Fluidity Evaluation Methods for Al-Mg Si Alloys", International Journal of Cast Material Research, vol. 19, pp. 94-97.

[13] Soejono tjitro et al (2001)," simulasi numerik pada distribusi tempratur proses pembekuan", jurnal teknologi, edisi no 3, tahun xv, September 2001. 